\title{
Simulating cadaveric dissection with virtual resources during Covid-19 in an undergraduate Anatomy Science programme
}

\author{
Ourania Varsou \\ University of Glasgow, UK \\ Michelle Welsh \\ University of Glasgow, UK
}

Keywords: anatomy; dissection; skills-based learning; technology enhanced learning and teaching; virtual learning; Covid-19.

\section{The challenge}

Many undergraduate degrees involve practice-based learning which teaches not only the technical skill itself, but also offers an opportunity to further develop subject-specific theoretical knowledge, as well as more transferable skills like teamwork and communication. Typically, in undergraduate human anatomy education, practice-based learning entails some degree of hands-on cadaveric dissection. This allows learners to develop technical skills (knowing how to correctly use equipment, identifying/cutting anatomical structures), whilst also expanding their anatomical knowledge and appreciating normal anatomical variation that may be absent in illustrations. Additionally, dissection can foster discipline-independent professional skills such as teamwork, communication, coping skills, ethical awareness, and respect (Ghosh, 2017).

Due to Covid-19, we had to find an alternative online method to deliver practice-based learning in our Bachelor of Science in Anatomy. Loss of this teaching could negatively impact on the student experience through: 1) missed opportunity for students to learn subject-specific knowledge, 2) reduced acquisition of subject-specific technical and transferable/professional skills (QAA, 2019), 3) negatively affecting student grades as dissection consolidates students' theoretical knowledge (Abdellatif, 2020), 4) impacting graduates' future career options, especially in vocations/training/further studies requiring technical skills. 
During the pandemic, we needed to ensure our online alternative taught subject-specific knowledge, whilst also addressing the other skills students develop during on-campus practice-based learning. As a range of different disciplinary programmes include similar practice-based teaching, our goal in this article is to plant the seeds for critical dialogues around what learning developers need to incorporate in virtual learning resources and to consider what online educational practices developed during Covid-19 are pedagogically beneficial to retain in the post-pandemic setting.

\section{The response}

To replicate the practice-based lab experience online, we aimed to minimise the cognitive load of delivering similar information from multiple platforms (Leppink and van den Heuvel, 2015), so we combined two commercial e-resources: a 3D real-time virtual anatomy atlas with videos of human cadaveric dissections. The atlas allows interactive exploration of anatomical structures, thus better simulating the active learning of dissection; however, it lacks anatomical variation and is less representative of real-life experience. Conversely, the videos provide realistic cadaveric anatomy and an indirect appreciation of dissection technical skills, but allow the students to be more passive (Laurillard, 2002). We embedded these e-resources into our existing teaching material (lab manuals) aiming to substitute on-campus dissection with alternative online approaches, whilst also enhancing pre-existing learning activities through the use of the interactive atlas (Puentedura, 2006). This approach was important to achieve our programme ILOs, while transitioning oncampus practice-based learning online.

Student access is a fundamental component for successful technology engagement (Bennett, 2014), therefore we ensured that all e-resources were embedded in a dedicated page for each teaching session in our virtual learning environment, promoting an immersive learning journey (Laurillard, 2002). In a survey of our year three students (61\% (23/38) response rate; ethics number: 200200083), all respondents were able to access the e-resources, with comments such as: 'They were embedded on the relevant lectures in Moodle which I found very useful as all the relevant information was easy to access'. 
On-campus practice-based learning sessions normally stimulate development of transferable/professional skills including communication, teamwork, and ethical awareness but using these e-resources as independent online learning tools made it difficult to replicate this experience. Therefore it was also important that we incorporated the eresources into our online live teaching sessions to allow students to work in groups to discuss what they were seeing, providing a more interactive experience, and helping them to develop communication and interpersonal skills. The use of cadaveric videos also meant the students were exposed to the ethical considerations of human dissection; openly discussing the use of cadavers in groups provided an opportunity to actively reflect on this experience which students might not otherwise have recognised.

\section{Recommendations}

We believe these resources supported student learning of the subject-specific knowledge with $83 \%$ of our students reporting that the atlas was useful for online learning of gross anatomy compared to $61 \%$ for the videos. This difference might reflect the more interactive nature of the atlas compared to passive engagement with videos. Despite this, we believe that returning to on-campus laboratories will be preferable to develop technical and transferable/professional skills that are challenging to fully simulate online, even with diverse virtual resources. $78 \%$ of our survey participants indicated a preference for keeping the atlas as part of on-campus teaching, with less being favourable towards the videos (57\%). In future, combining on-campus labs with the use of a 3D atlas might promote better understanding of anatomical information and improve long-term knowledge retention beyond that of isolated on-campus sessions (Peterson and Mlynarczyk, 2016). The e-resources could be useful for pre-laboratory work, helping students better prepare for these and thus gain more from their on-campus experience (Nordmann et al., 2020). For example, they could provide a gentle introduction to cadavers allowing first-time learners to overcome any potential anxiety or ethical concerns around exposure to human cadavers and help them prepare for dissection.

Based on our experience, the use of virtual resources to replicate on-campus practicebased lab experience only partially met all the learning requirements for our students to support their learning and future employability. Both e-resources clearly supported subjectspecific knowledge student learning, whether these were used independently by students 
or as part of an interactive class learning experience. However, neither demonstrated reallife anatomical variation which would be present in on-campus lab experience. Although the videos went some way to demonstrate technical skills, such as correct use and handling of equipment with knowing how to cut anatomical structures, we do not believe that passively observing these could replace the hands-on active experience from the lab. Similarly, neither e-resource used independently is likely to help students develop the transferable/professional skills such as teamwork and communication, but integrating them into online live sessions where students join staff and peers to interact with these resources offers an opportunity to acquire and develop such skills. Finally, the videos offered an inactive exposure to human cadavers which, whilst it cannot replace students gaining hands-on experience with a body and the coping skills, ethical awareness, and respect that this experience fosters, can form the basis for discussions around these topics. With increasing student numbers and shortage of access to on-campus lab space and cadavers, these e-resources could provide a complementary resource to aid anatomy teaching if thoughtfully integrated into courses.

\section{Acknowledgments}

We would like to thank Dr Vicki Dale for providing general comments about the structure and style of our manuscript.

Note: Part of this work was presented, as a short talk, at the 14th Annual University of Glasgow Learning and Teaching Conference in June 2021 and, as a flash talk, at the Anatomical Society Summer Meeting in July 2021.

\section{References}

Abdellatif, H. (2020) 'Time spent in practicing dissection correlated with improvement in anatomical knowledge of students: experimental study in an integrated learning program', Cureus, 12(4), p.e7558. https://doi.org/10.7759/cureus.7558. 
Bennett, E. (2014) 'Learning from the early adopters: developing the digital practitioner', Research in Learning Technology, 22, p.21453.

https://doi.org/10.3402/rlt.v22.21453

Ghosh, S. K. (2017) 'Cadaveric dissection as an educational tool for anatomical sciences in the 21st century', Anatomical Sciences Education, 10(3), pp.286-299. https://doi.org/10.1002/ase.1649.

Laurillard, D. (2002) Rethinking university teaching: a conversational framework for the effective use of learning technologies. London: Routledge.

Leppink, J. and van den Heuvel, A. (2015) 'The evolution of cognitive load theory and its application to medical education', Perspectives on Medical Education, 4(3), pp.119127. https://doi.org/10.1007/s40037-015-0192-x.

Nordmann, E., Horlin, C., Hutchison, J., Murray, J. A., Robson, L., Seery, M. K. and MacKay, J. R. (2020) 'Ten simple rules for supporting a temporary online pivot in higher education', PLoS Comput Biol, 16(10), p.e1008242. https://doi.org/10.1371/journal.pcbi.1008242.

Peterson, D. C. and Mlynarczyk, G. S. (2016) 'Analysis of traditional versus threedimensional augmented curriculum on anatomical learning outcome measures', Anatomical Sciences Education, 9(6), pp.529-536. https://doi.org/10.1002/ase.1612.

Puentedura, R. R. (2006) Transformation, technology, and education [blog post]. Available at: http://hippasus.com/resources/tte/ (Accessed: 7 June 2021).

QAA (2019) Subject benchmark statement: Biomedical Sciences [online resource]. Available at: https://www.qaa.ac.uk/docs/qaa/subject-benchmarkstatements/subject-benchmark-statement-biomedicalsciences.pdf?sfvrsn=2bf2c881 12 (Accessed: 7 June 2021).

\section{Author details}


Ourania Varsou is a Lecturer in Anatomy at the School of Life Sciences, University of

Glasgow. Ourania's research includes imaging with a strong focus on ultrasound, clinically applied anatomy, and scholarship of teaching and learning.

Michelle Welsh is a Senior Lecturer in Anatomy at the School of Life Sciences, University of Glasgow. Michelle's research has focussed on reproductive biology and embryology as well as scholarship of teaching and learning. 